\title{
Effects of Overactive Bladder Symptoms in Stroke Patients' Health Related Quality of Life and Their Performance Scale
}

\author{
Hannah Pyo, $\mathrm{MD}^{1}$, Bo Ra Kim, MD ${ }^{1}$, Mina Park, $\mathrm{MD}^{1}$, Jeong Hee Hong, MD², Eun Joo Kim, MD ${ }^{1}$ \\ ${ }^{1}$ Department of Physical Medicine and Rehabilitation, National Rehabilitation Center, Seoul; \\ ${ }^{2}$ Department of Urology, Dankook University College of Medicine, Cheonan, Korea
}

\begin{abstract}
Objective To identify the effects of overactive bladder (OAB) symptoms on the health-related quality of life (HRQOL) in stroke patients since OAB symptoms are common in such patients, but their effects on stroke rehabilitation over time are unclear.

Methods This study included 30 post-acute stroke patients who had been admitted for rehabilitation treatments. All participants completed a questionnaire evaluating urinary symptoms, including the Overactive Bladder Symptom Score (OABSS) and general HRQOL with a Short-Form 36 (SF-36) health survey. We assessed their performance in terms of the Function Ambulation Category, Modified Rankin Scale (MRS), Modified Barthel Index, and Mini-Mental State Examination (MMSE). All assessments were carried out twice at baseline and at 3 months. We divided patients into an OAB and non-OAB group with OABSS. A correlation analysis and multivariate regression were then performed.

Results All performance scales showed an improvement over 3 months in the non-OAB group ( $\mathrm{n}=18 ; \mathrm{p}<0.02)$, but, MRS and MMSE scores did not improve significantly in the OAB group $(n=12)(p=0.15$ and $p=0.20$, respectively). In the $\mathrm{OAB}$ group, the vitality and mental health scores significantly decreased over 3 months $(\mathrm{p}=0.011$ and $\mathrm{p}=0,041$, respectively), and the mental component summary (MCS) score showed a marginal decrease over 3 months $(\mathrm{p}=0.05)$. A multivariate regression analysis revealed that $\mathrm{OAB}$ symptoms were negatively correlated with the 3 months MCS score ( $\mathrm{B}=-8.15, \mathrm{p}=0.034)$.

Conclusion These results indicated that OAB symptoms could have negative effects on HRQOL and performance in patients suffering from a stroke.
\end{abstract}

Keywords Stroke, Rehabilitation, Overactive bladder, Quality of life

Received February 27, 2017; Accepted May 2, 2017

Corresponding author: Eun Joo Kim

Department of Physical Medicine and Rehabilitation, National Rehabilitation Center, 58 Samgaksan-ro, Gangbuk-gu, Seoul 01022, Korea. Tel: +82-2901-1633, Fax: +82-2-901-1591, E-mail: silverzookim@gmail.com

ORCID: Hannah Pyo (http://orcid.org/0000-0001-8646-4065); Bo Ra Kim (http://orcid.org/0000-0003-1068-9246); Mina Park (http://orcid.org/00000002-0996-4522); Jeong Hee Hong (http://orcid.org/0000-0003-2937-8552); Eun Joo Kim (http://orcid.org/0000-0001-6166-7886).

(c) This is an open-access article distributed under the terms of the Creative Commons Attribution Non-Commercial License (http://creativecommons.org/ licenses/by-nc/4.0) which permits unrestricted noncommercial use, distribution, and reproduction in any medium, provided the original work is properly cited. Copyright $\odot 2017$ by Korean Academy of Rehabilitation Medicine 


\section{INTRODUCTION}

Stroke causes significant changes in the urinary system, and various urinary symptoms appear. Urinary incontinence is a known predictor of moderate to severe stroke [1], and the prevalence of lower urinary tract symptoms (LUTS) after a stroke was higher in stroke patients (64\%) than in the general population (34\%) [2].

An overactive bladder $(\mathrm{OAB})$ is defined by the International Continence Society for patients with urinary urgency, with or without urge incontinence, and with urinary frequency and nocturia, but in the absence of infection or obvious neoplastic, metabolic, or other pathologies [3]. OAB is related to physical and mental health as well as to other symptoms, including skin breakdown due to leakage, sleep disturbance, fall-related injuries, depression, prolonged hospital stays, admission to a nursing home, and lower quality of life (QOL) $[4,5]$. Stroke is known as a risk factor for $\mathrm{OAB}$ [6], and the $\mathrm{OAB}$ prevalence is $12.4 \%-53.1 \%$ in elderly adults [7-9]. However, little is known about the prevalence of OAB in stroke patients. Itoh et al. [10] found that of 500 stroke patients, $28 \%$ had OAB.

Although $\mathrm{OAB}$ is considered to be highly prevalent, its etiology remains unknown. The pathophysiology of $\mathrm{OAB}$ is complex and involves both peripheral and central nervous system factors. An increased afferent activity, decreased capacity to process afferent information, decreased suprapontine inhibition, and increased sensitivity to contraction-mediating transmitters are all potential central nervous system causes of $\mathrm{OAB}$ that can be induced by stroke.

$\mathrm{OAB}$ is an embarrassing condition that interferes with social functioning and daily living activities. However, caregivers and medical staff can overlook a diagnosis of $\mathrm{OAB}$, which may result in an undertreatment of its symptoms. In contrast, urinary incontinence that obviously lowers the health-related QOL (HRQOL) of patients and caregivers can easily be noticed and treated [11]. Although a large proportion of stroke patients seem to have low HRQOL due to OAB symptoms, few studies have investigated the effect of $\mathrm{OAB}$ symptoms on stroke patients' HRQOL, especially during rehabilitation.

To understand the effect of OAB symptoms in stroke patients' HRQOL, we conducted a questionnaire-based survey at baseline and at 3 months of follow-up and ana- lyzed the results together with clinical data.

\section{MATERIALS AND METHODS}

\section{Patients and study design}

We screened patients who had experienced a stroke and who were admitted to the rehabilitation center between March 2014 and May 2016. The inclusion criteria were as follows: (1) the patient was diagnosed with stroke, (2) the lesion was confirmed via brain magnetic resonance imaging or computed tomography imaging, (3) more than 1 month passed after the onset of the stroke, (4) the patient's age was between 20 to 80 years, (5) the patients maintained intact cognitive function and were able to understand and complete the questionnaire. Patients with urinary tract infection, chronic renal failure, pelvic organ prolapse, urethral stricture, prostate-related operation history, prostate specific antigen (PSA) of more than $4.0 \mathrm{ng} / \mathrm{mL}$, history of bladder cancer, severe medical comorbidities, and cognitive impairment disorder were excluded. Patients who were unable to void spontaneously or whose postvoid residual urine volume was greater than $300 \mathrm{~mL}$ [12], who had OAB symptoms or urinary incontinence from 6 months before onset, and who did not complete the questionnaire were also excluded.

A total of 30 stroke patients (14 female, 16 male) were enrolled in this study and signed the informed consent forms. Participants were divided into two groups: an $\mathrm{OAB}$ group and non-OAB group according to the Overactive Bladder Symptom Score (OABSS), which is a screening tool for OAB symptoms. The OAB group was defined with an urgency score of 2 or more and a total score of 3 or more, in accordance with previous studies [13].

The participants were surveyed to evaluate their HRQOL, and their performance was assessed twice: at the time of enrollment and 3 months later after the baseline survey. A transrectal ultrasonography (TRUS) was performed, and the PSA level was assessed in men. All patients were subjected to uroflowmetry to evaluate the urine flow rate.

The study was approved by the Institutional Review Board of the National Rehabilitation Center (IRB No. NRC-2014-01-006), and all participants gave written informed consent. 
Table 1. Baseline demographics, performance scale, questionnaire in $\mathrm{OAB}$ and non-OAB groups

\begin{tabular}{|c|c|c|c|c|}
\hline Characteristic & Total $(n=30)$ & OAB $(n=12)$ & non-OAB $(n=18)$ & p-value \\
\hline \multicolumn{5}{|l|}{ Gender } \\
\hline Male & $16(53)$ & $6(50)$ & $10(55.6)$ & 1.000 \\
\hline Female & $14(47)$ & $6(50)$ & $8(44.4)$ & \\
\hline Age (yr) & $58.9 \pm 11.1$ & $58.5 \pm 13.4$ & $59.2 \pm 9.6$ & 0.875 \\
\hline$<60$ & $15(50)$ & $6(50)$ & $9(50)$ & \\
\hline$\geq 60$ & $15(50)$ & $6(50)$ & $9(50)$ & \\
\hline \multicolumn{5}{|l|}{ Subtype of stroke } \\
\hline Infarction & $16(53.3)$ & $5(41.7)$ & $11(61.1)$ & 0.579 \\
\hline MCA & $6(37.5)$ & $3(60.0)$ & $3(27.3)$ & \\
\hline ICA & $1(6.3)$ & $1(20.0)$ & - & \\
\hline Lacunar & $7(43.8)$ & $1(20.0)$ & $6(54.5)$ & \\
\hline Other & $2(12.5)$ & - & $2(18.2)$ & \\
\hline Hemorrhage & $12(40.0)$ & $6(50.0)$ & $6(33.3)$ & \\
\hline Basal ganglia & $6(50.0)$ & $3(50.0)$ & $3(50.0)$ & \\
\hline Thalamus & $2(16.7)$ & $1(16.7)$ & $1(16.7)$ & \\
\hline Cerebellum & $2(16.7)$ & $1(16.7)$ & $1(16.7)$ & \\
\hline Other & $2(16.7)$ & $1(16.7)$ & $1(16.7)$ & \\
\hline Both & $2(6.7)$ & $1(8.3)$ & $1(5.6)$ & \\
\hline \multicolumn{5}{|l|}{ Localization } \\
\hline Right hemisphere & $20(66.7)$ & $9(75.0)$ & $11(61.1)$ & 0.220 \\
\hline Left hemisphere & $7(23.3)$ & $1(8.3)$ & $6(33.3)$ & \\
\hline Bilateral & $3(10.0)$ & $2(16.7)$ & $1(5.6)$ & \\
\hline \multicolumn{5}{|l|}{ Past medical history } \\
\hline Hypertension & $14(46.7)$ & $7(58.3)$ & $9(50.0)$ & 0.940 \\
\hline Diabetes mellitus & $24(80.0)$ & $5(41.7)$ & $9(50.0)$ & 0.660 \\
\hline Other cardiovascular disease & $6(20.0)$ & $2(16.7)$ & $4(22.2)$ & 0.576 \\
\hline Duration of stroke (mo) & $4.6 \pm 5.7$ & $6.0 \pm 2.2$ & $3.7 \pm 4.1$ & 0.292 \\
\hline Use of anticholinergics & $4(13.4)$ & $2(16.7)$ & $2(11.1)$ & 0.661 \\
\hline \multicolumn{5}{|l|}{ Uroflowmetry } \\
\hline $\mathrm{Qmax}(\mathrm{mL} / \mathrm{s})$ & $14.7 \pm 8.8$ & $17.5 \pm 12.2$ & $12.9 \pm 5.2$ & 0.243 \\
\hline Postvoid residual volume (mL) & $20.2 \pm 36.9$ & $19.8 \pm 50.1$ & $20.5 \pm 26.5$ & 0.962 \\
\hline Prostate volume $^{\mathrm{a})}(\mathrm{mL})$ & $21.1 \pm 10.9$ & $24.8 \pm 14.4$ & $18.4 \pm 7.3$ & 0.297 \\
\hline Serum $\operatorname{PSA}^{\text {a) }}(\mathrm{ng} / \mathrm{mL})$ & $1.2 \pm 0.8$ & $1.0 \pm 0.7$ & $1.2 \pm 0.8$ & 0.591 \\
\hline OABSS & $3.9 \pm 2.9$ & $6.8 \pm 2.0$ & $2.0 \pm 1.4$ & $<0.001$ \\
\hline \multicolumn{5}{|l|}{ IPSS } \\
\hline Total score & $9.1(7.9)$ & $15.3(7.8)$ & $5.1(4.9)$ & $<0.001$ \\
\hline Storage symptom score (question $2+4+7$ ) & $4.5(3.8)$ & $7.3(4.0)$ & $2.4(3.4)$ & $<0.001$ \\
\hline Voiding symptom score (question $1+3+5+6$ ) & $4.6(4.8)$ & $8.0(4.8)$ & $2.4(3.4)$ & 0.001 \\
\hline
\end{tabular}

Values are presented as number (\%) or mean \pm standard deviation.

$\mathrm{OAB}$, overactive bladder; MCA, middle cerebral artery; ICA, internal carotid artery; $\mathrm{CH}$, intracranial hemorrhage; Qmax, maximum flow rate; PSA, prostate-specific antigen; OABSS, Overactive Bladder Symptom Score; IPSS, International Prostate Symptom Score.

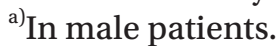




\section{Questionnaire}

OABSS was developed to screen patients with $\mathrm{OAB}$ symptoms and to evaluate the severity of OAB symptoms $[14,15]$, and it was recorded in all patients. It consists of four questions covering the daytime frequency, nocturia, urgency, and urgency incontinence, with maximal scores of $2,3,5$, and 5 , respectively. Since urinary urgency is the core symptom of $\mathrm{OAB}$, the $\mathrm{OAB}$ group was defined with an urgency score of 2 and total OABSS score of 3 or more [13].

We conducted the survey to evaluate the HRQOL using the Short Form 36 health survey (SF-36) version 2. SF-36 evaluates the following 8 physical and mental health areas: physical functioning (PF), physical role functioning (RP), bodily pain (BP), general health (GH), vitality (VT), social role functioning (SF), emotional role functioning (RE), and mental health (MH). Each of the 8 areas was scored on a scale of $0-100$, with a higher score indicating better subjective health. These scores were then calculated from the questionnaires responses as previously described. The physical component summary (PCS) and mental component summary (MCS) measures are calculated from these 8 scales using algorithms recommended by the instrument developers [16]. This study was conducted with permission from QualityMetric Inc., Lincoln, RI, USA.

In addition, the International Prostate Symptom Score (IPSS), incontinence quality of life (I-QOL), and Overactive Bladder Questionnaire (OAB-Q) were conducted to identify urinary symptoms.

\section{Clinical data and functional status score}

At the time of enrollment, we measured the prostate volume using TRUS in men to rule out benign prostate hyperplasia (BPH), which is very common in elderly men. Patients suspected by an urologist of having BPH were excluded. All patients were examined via uroflowmetry to evaluate the urine flow rate, and clinical information was collected, including types and lesion of stroke, onset of stroke, underlying hypertension, diabetes, and

Table 2. Cross-sectional analysis of subjects at baseline and 3-month follow-up

\begin{tabular}{|c|c|c|c|c|c|c|}
\hline & \multicolumn{3}{|c|}{ Baseline } & \multicolumn{3}{|c|}{ 3-mo follow-up } \\
\hline & $\begin{array}{c}\text { OAB } \\
(n=12)\end{array}$ & $\begin{array}{c}\text { Non-OAB } \\
(n=18)\end{array}$ & p-value & $\begin{array}{c}\text { OAB } \\
(n=12)\end{array}$ & $\begin{array}{c}\text { Non-OAB } \\
(n=18)\end{array}$ & p-value \\
\hline \multicolumn{7}{|c|}{ Performance scale } \\
\hline FAC & $1.8 \pm 1.4$ & $2.6 \pm 1.0$ & 0.177 & $2.6 \pm 1.1$ & $3.3 \pm 1.1$ & 0.07 \\
\hline MRS & $3.6 \pm 0.9$ & $3.3 \pm 0.9$ & 0.525 & $3.3 \pm 0.6$ & $2.6 \pm 0.9$ & 0.034 \\
\hline MBI & $64.5 \pm 18.7$ & $66.3 \pm 17.1$ & 0.882 & $71.3 \pm 19.2$ & $74.9 \pm 14.5$ & 0.626 \\
\hline MMSE & $26.5 \pm 4.4$ & $26.5 \pm 3.0$ & 0.622 & $27.5 \pm 2.7$ & $28.2 \pm 2.4$ & 0.568 \\
\hline \multicolumn{7}{|l|}{ SF-36 } \\
\hline PCS & $34.3 \pm 8.0$ & $37.6 \pm 9.2$ & 0.352 & $36.0 \pm 8.9$ & $41.4 \pm 9.34$ & 0.138 \\
\hline MCS & $40.3 \pm 7.3$ & $44.2 \pm 15.0$ & 0.352 & $35.6 \pm 10.9$ & $41.6 \pm 9.4$ & 0.075 \\
\hline PF & $32.1 \pm 32.4$ & $27.8 \pm 35.9$ & 0.602 & $29.2 \pm 25.9$ & $50.8 \pm 33.7$ & 0.095 \\
\hline $\mathrm{RP}$ & $30.7 \pm 29.9$ & $42.7 \pm 44.5$ & 0.723 & $38.0 \pm 31.9$ & $37.2 \pm 27.7$ & 0.917 \\
\hline BP & $35.8 \pm 28.5$ & $49.7 \pm 26.7$ & 0.185 & $43.3 \pm 33.4$ & $55.8 \pm 28.4$ & 0.267 \\
\hline GH & $43.1 \pm 16.9$ & $56.4 \pm 21.3$ & 0.065 & $38.8 \pm 16.0$ & $55.2 \pm 19.6$ & 0.031 \\
\hline VT & $42.2 \pm 16.2$ & $55.2 \pm 24.9$ & 0.134 & $27.1 \pm 12.0$ & $52.1 \pm 15.9$ & $<0.001$ \\
\hline SF & $49.0 \pm 24.1$ & $56.9 \pm 37.9$ & 0.518 & $42.7 \pm 34.3$ & $57.6 \pm 21.1$ & 0.305 \\
\hline $\mathrm{RE}$ & $34.0 \pm 30.2$ & $51.4 \pm 48.9$ & 0.439 & $46.5 \pm 42.3$ & $41.2 \pm 30.8$ & 0.917 \\
\hline MH & $60.8 \pm 16.4$ & $57.8 \pm 24.9$ & 0.95 & $44.2 \pm 22.9$ & $63.9 \pm 14.1$ & 0.01 \\
\hline
\end{tabular}

Values are presented as mean \pm standard deviation.

$\mathrm{OAB}$, overactive bladder; FAC, Functional Ambulation Category; MRS, Modified Rankin Scale; MBI, Modified Barthel Index; MMSE, Mini-Mental State Examination; SF-36 v2, short form-36 version 2; PCS, physical component summary; MCS, mental component summary; PF, physical functioning; RP, role physical; BP, bodily pain; GH, general health; VT, vitality; SF, social functioning; RE, role emotional; MH, mental health. 
other cardiovascular diseases. The performance scores, such as Function Ambulation Category (FAC), Modified Rankin Scale (MRS), Modified Barthel Index (MBI), and Mini-Mental State Examination (MMSE), were assessed by clinical doctors at baseline and at 3 months later.

\section{Statistical analysis}

The baseline characteristics were compared between the $\mathrm{OAB}$ and non-OAB groups. For the comparison, t-test and chi-square test were used. We used Mann-Whitney U-test to compare two groups at baseline and at 3 months of follow-up. A longitudinal analysis was assessed by a Wilcoxon signed-rank test. We used a correlation analysis and a multivariate regression to assess whether the $\mathrm{OAB}$ symptoms were associated with 3-month MCS. The variables obtained through baseline surveys were selected using the backward elimination method during a multiple regression analysis. The statistical significance was confirmed using a goodness-of-fit test and a significance test of the regression coefficient. The statistical significance was considered when $p$-value was $\leq 0.05$, and the data were analyzed with the SPSS ver. 21 statistical package (IBM, Armonk, NY, USA).

\section{RESULTS}

\section{Participant characteristics}

From March 2014 to May 2016, a total of 39 stroke patients signed a consent form, but 9 refused the last survey. The mean age of 30 participants was 58.9 years, and the mean onset duration of stroke was 4.6 months. We divided subjects into two groups: OAB group $(n=12)$ and non-OAB group $(n=18)$. The general characteristics and demographic information of the 30 subjects and the differences between the two groups are presented in Table 1 . Only one patient had aphasia, and this patient was in the non-OAB group.

OABSS was evaluated twice. Three patients reported aggravation of $\mathrm{OAB}$ symptoms over 3 months, and there was no urinary tract infection or other urinary related events. In the initial evaluation, 4 patients were using anticholinergics, and there was no restriction to change medication in this study. All 4 patients maintained the medication, and 1 patient showed deterioration in the OABSS score. After the initial evaluation, 4 patients started taking anticholinergics due to $\mathrm{OAB}$ symptoms, and the rest of the patients in the $\mathrm{OAB}$ group were symptomatic but did not take medication.

\section{HROOL and OAB symptoms}

Looking at SF-36, which presents the general HRQOL of the patients, both PCS and MCS scores showed no difference between the $\mathrm{OAB}$ group and non-OAB group at both baseline and at 3-month follow-up (Table 2). In a longitudinal analysis, the MCS score showed a marginal decrease over time only in the OAB group $(\mathrm{p}=0.05)$ (Table 3 , Fig. 1). As we look into the subareas of SF-36, no difference was seen between the two groups at baseline, but the general health, vitality, and mental health areas showed a lower score in the OAB group compared to the

Table 3. Longitudinal analysis of subjects at baseline and 3-month follow-up

\begin{tabular}{|c|c|c|c|c|c|c|}
\hline & \multicolumn{3}{|c|}{ OAB $(n=12)$} & \multicolumn{3}{|c|}{ Non-OAB $(n=18)$} \\
\hline & Baseline & 3-mo follow-up & p-value & Baseline & 3-mo follow-up & p-value \\
\hline \multicolumn{7}{|l|}{ SF-36 } \\
\hline PF & $32.1 \pm 32.4$ & $29.2 \pm 25.9$ & 0.799 & $27.8 \pm 35.9$ & $50.8 \pm 33.7$ & 0.034 \\
\hline $\mathrm{RP}$ & $30.7 \pm 29.9$ & $38.0 \pm 31.9$ & 0.441 & $42.7 \pm 44.5$ & $37.2 \pm 27.7$ & 0.705 \\
\hline $\mathrm{BP}$ & $35.8 \pm 28.5$ & $43.3 \pm 33.4$ & 0.284 & $49.7 \pm 26.7$ & $55.8 \pm 28.4$ & 0.293 \\
\hline $\mathrm{GH}$ & $43.1 \pm 16.9$ & $38.8 \pm 16.0$ & 0.959 & $56.4 \pm 21.3$ & $55.2 \pm 19.6$ & 0.623 \\
\hline VT & $42.2 \pm 16.2$ & $27.1 \pm 12.0$ & 0.012 & $55.2 \pm 24.9$ & $52.1 \pm 15.9$ & 0.46 \\
\hline SF & $49.0 \pm 24.1$ & $42.7 \pm 34.3$ & 0.368 & $56.9 \pm 37.9$ & $57.6 \pm 21.1$ & 0.896 \\
\hline $\mathrm{RE}$ & $34.0 \pm 30.2$ & $46.5 \pm 42.3$ & 0.12 & $51.4 \pm 48.9$ & $41.2 \pm 30.8$ & 0.287 \\
\hline $\mathrm{MH}$ & $60.8 \pm 16.4$ & $44.2 \pm 22.9$ & 0.041 & $57.8 \pm 24.9$ & $63.9 \pm 14.1$ & 0.399 \\
\hline
\end{tabular}

Values are presented as mean \pm standard deviation.

$\mathrm{OAB}$, overactive bladder; SF-36 v2, short form-36 version 2; PF, physical functioning; RP, role physical; BP, bodily pain; $\mathrm{GH}$, general health; VT, vitality; SF, social functioning; RE, role emotional; $\mathrm{MH}$, mental health. 
(A)

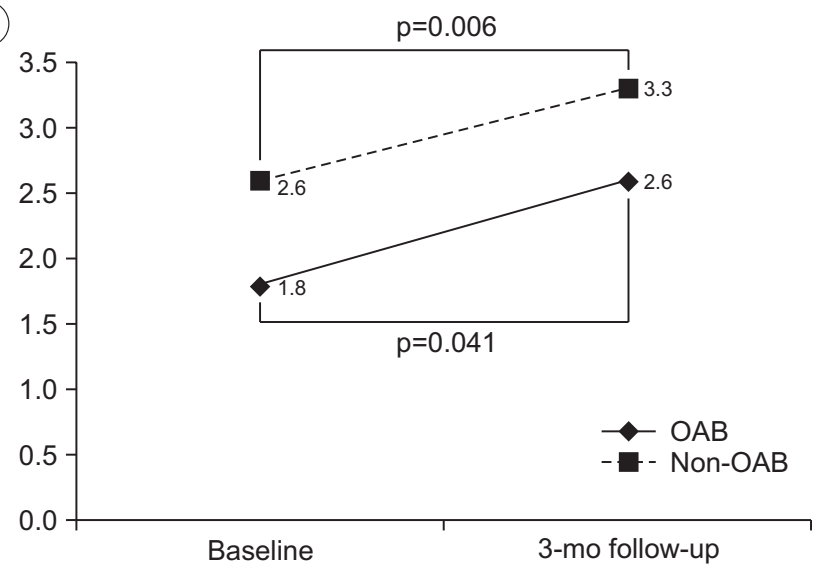

(C)

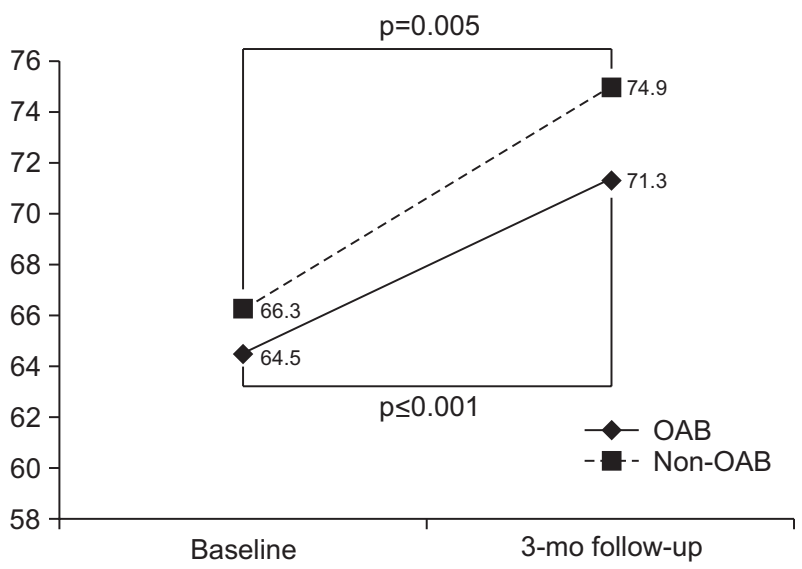

(E)

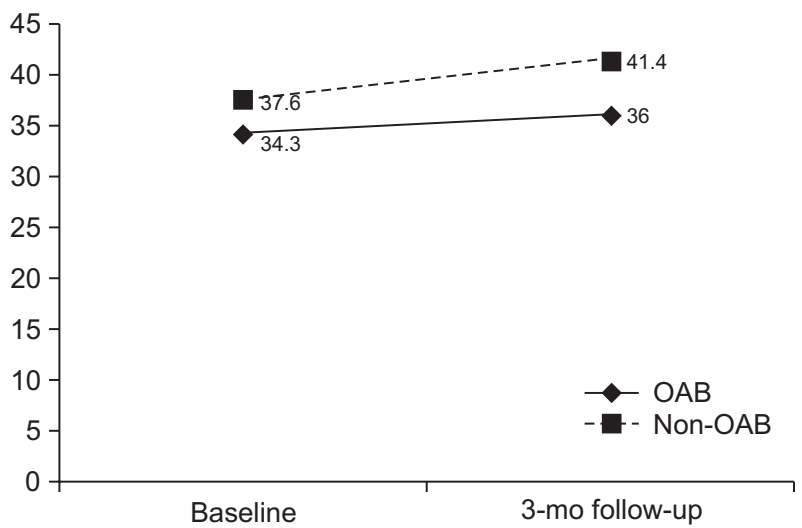

(B)

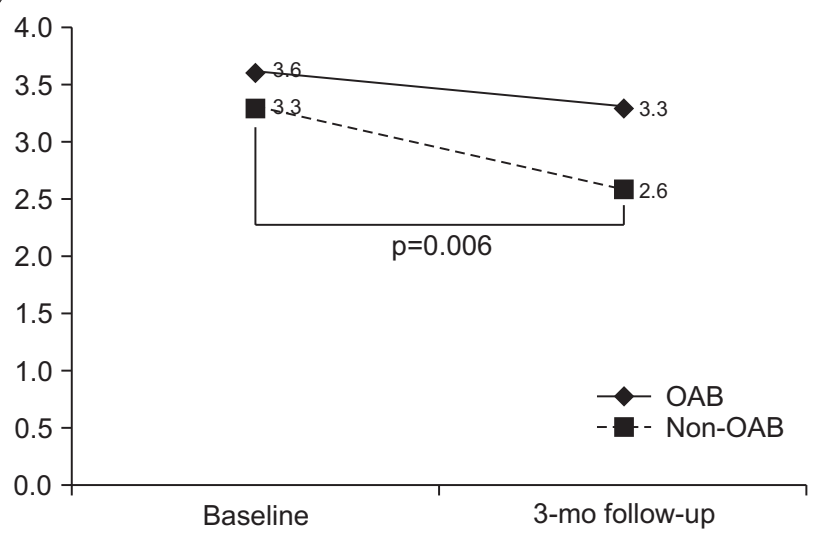

(D)

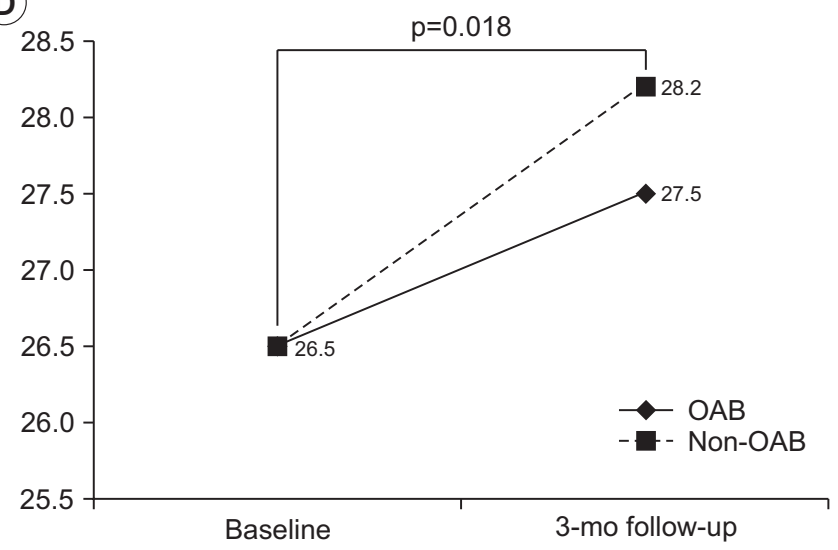

(F)

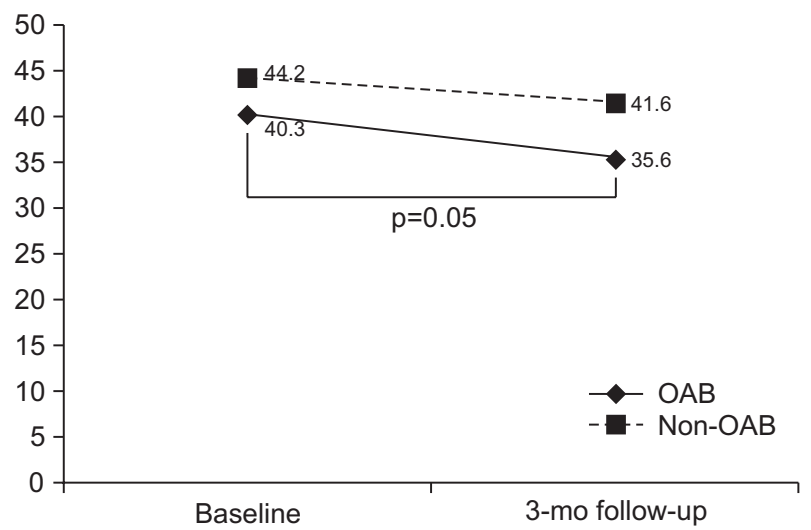

Fig. 1. Changes in the performance scale and SF-36 scores over 3 months. (A) Functional Ambulation Category, (B) Modified Rankin Scale, (C) Modified Barthel Index, (D) Mini-Mental State Examination, (E) physical component summary, and $(\mathrm{F})$ mental component summary. $\mathrm{OAB}$, overactive bladder.

non-OAB group at 3 months of follow-up (Table 2). The vitality and mental health areas had a significant decrease in scores over 3 months in the OAB group ( $\mathrm{p}=0.011$ and $\mathrm{p}=0.041$, respectively) (Table 3 ). In a multivariate regression, the presence of $\mathrm{OAB}$ symptoms was significant- ly associated with lower MCS scores at 3 months $(B=-8.15$, $\mathrm{p}=0.034$ ) (Table 4). Therefore, the OAB symptoms seem to have a negative effect on the mental component of the HRQOL. Other subareas of SF-36 showed no difference at 3 months of follow-up compared to that at baseline, but 
Table 4. Results of multivariate regression with MCS score in SF-36 at 3-month follow-up as the dependent variable $(n=30)$

\begin{tabular}{lccc}
\hline & B & 95\% CI & p-value \\
\hline Subtype of stroke & 4.08 & -1.70 to 9.85 & 0.158 \\
Hypertension & 5.60 & -1.39 to 12.60 & 0.112 \\
MMSE & -0.52 & -1.55 to 0.52 & 0.315 \\
OAB & -8.15 & -15.61 to -0.68 & 0.034 \\
\hline
\end{tabular}

MCS, mental component summary; SF-36, short form36; CI, confidence interval; MMSE, Mini-Mental State Examination; $\mathrm{OAB}$, overactive bladder.

the physical functioning area showed an improvement at 3-month follow-up ( $\mathrm{p}=0.03$ ).

The I-QOL total score and HRQOL score of OABQ showed no difference between the two groups ( $\mathrm{p}=0.54$ and $\mathrm{p}=0.37$ respectively), but the questions regarding lower urinary tract symptoms in OABQ showed a significant difference between the two groups $(\mathrm{p}<0.001)$.

\section{Performance scale scores and OAB symptoms}

In the non-OAB group, all patient performance scales showed an improvement over time (all $\mathrm{p}<0.02)$. However, in the OAB group, the FAC and MBI showed an improvement ( $\mathrm{p}=0.04$ and 0.005 , respectively), but MRS and MMSE did not improve significantly $(\mathrm{p}=0.15$ and $\mathrm{p}=0.20$, respectively) (Table 2). At 3-month follow-up, the MRS scores were lower in the non-OAB group $(\mathrm{p}=0.034)$, indicating less disability.

\section{Assessment of urinary symptoms}

At the baseline, the use of anticholinergics and the results of the uroflowmetry and TRUS showed no differences between the $\mathrm{OAB}$ and non-OAB groups (Table 1). The international prostate symptom score showed a significant difference in both storage and voiding scores between the two groups at baseline, but there was no longitudinal change over 3 months in both the $\mathrm{OAB}$ group $(\mathrm{p}=0.34)$ and non-OAB group $(\mathrm{p}=0.86)$.

\section{DISCUSSION}

We prospectively assessed the HRQOL and performance scale scores at baseline and at 3 months of followup of post-acute stroke patients. Patients who had OAB symptoms seemed to have greater burden in the mental aspect of HRQOL at the 3-month follow-up. Moreover, there is a possibility that the OAB symptoms affect the physical and cognitive performance of stroke patients.

Urinary incontinence has been reported to be a predictor of mortality and poor functional outcomes after a stroke [1]. Urinary incontinence negatively affects the QOL in the general population, especially in patients with stroke who have neurologic deficits such as dysphagia, visual field defects, motor weaknesses, and cognition and language impairments [17]. In addition to urinary incontinence, $\mathrm{OAB}$ symptoms also cause considerable inconvenience to stroke patients. However, previous studies have mainly focused on the prevalence of urinary incontinence after stroke. Only a few studies were carried out for $\mathrm{OAB}$ symptoms, such as urinary urgency, frequency, and nocturia, and these studies used a simple questionnaire for community-based stroke patients [2,17-19]. Since there was no study on the effect of OAB symptoms during rehabilitation treatments, we found that the vitality and mental health scores of SF-36 exhibited a significant decrease over 3 months in the OAB group, and the presence of $\mathrm{OAB}$ symptoms was significantly associated with a lower MCS score at 3 months of follow-up. The $\mathrm{OAB}$ symptoms seem to have a negative effect on the mental component of the HRQOL. Although this regression model explains only $22 \%$ of the variance in the MCS, it can add strength to our hypothesis.

Several prognostic factors for $\mathrm{OAB}$ have been reported in the general population. For men, comorbidities, including arthritis, depression, heart disease, hypertension, mobility limitations, neurological conditions, recurrent urinary tract infection, $\mathrm{BPH}$, and prostatitis, are suggested to be predictors of OAB $[7,20]$. BPH associated with LUTS prevalence rates ranged from 50\%-75\% among 50 years and older men to $80 \%$ among 70 years and older men [21]. Therefore, an objective evaluation of lower urinary tract symptoms due to BPH is necessary to minimize bias in elderly men. We underwent TRUS by an urologist to assess the prostate in male participants.

Itoh et al. [10] analyzed questionnaires on 500 stroke patients. OAB was identified in $28 \%$ of patients, with lower HROQL scores in both the physical and mental components of SF-8. The elderly and male patients were also associated with OAB. Compared with a previous study, we found no difference between the two groups in the initial HRQOL evaluation, but HRQOL scores were lower 
in patients who had OAB symptoms only in the mental component at the 3-month follow-up. Moreover, we can see the change in HRQOL by evaluating SF-36 twice in 3 months.

We found that MRS and MMSE showed less of an improvement in the $\mathrm{OAB}$ group than in the non-OAB group, and the physical functioning score of SF-36 showed a significantly higher score at 3 months of follow-up, compared to baseline $(\mathrm{p}=0.034)$. We might infer the possibility that $\mathrm{OAB}$ symptoms may affect the performance in patients with stroke. Therefore, a further study with more patients and a longer follow-up period is needed to prove this hypothesis.

This study had several limitations. Although this was a prospective study, it was conducted in a single institution with a small number of patients. Only patients with an adequate cognitive level to respond to the questionnaire and with the bladder control to participate in uroflowmetry were included in this study. In addition, due to the small number of patients, it is difficult to analyze the relationship between the changes in HQOL and $\mathrm{OAB}$ symptoms according to the use of medication. Therefore, larger prospective investigations are required to overcome these limitations and to determine the precise effects of OAB symptoms after stroke.

In addition to the negative impact of the $\mathrm{OAB}$ symptoms on the HRQOL of stroke patients, the detection and proper treatment of $\mathrm{OAB}$ symptoms in stroke patients should be encouraged to improve their HRQOL.

In conclusion, our findings indicate that $\mathrm{OAB}$ symptoms have negative effects on the physical and cognitive performance of stroke patients, and as the recovery process progresses, the burden of $\mathrm{OAB}$ symptoms may become more pronounced on HRQOL, especially regarding the mental component. Therefore, OAB symptoms should not be overlooked, and they need to be treated in stroke patients.

\section{CONFLICT OF INTEREST}

No potential conflict of interest relevant to this article was reported.

\section{REFERENCES}

1. Brittain KR, Peet SM, Castleden CM. Stroke and in- continence. Stroke 1998;29:524-8.

2. Brittain KR, Perry SI, Peet SM, Shaw C, Dallosso H, Assassa RP, et al. Prevalence and impact of urinary symptoms among community-dwelling stroke survivors. Stroke 2000;31:886-91.

3. Abrams P, Cardozo L, Fall M, Griffiths D, Rosier P, Ulmsten $\mathrm{U}$, et al. The standardisation of terminology of lower urinary tract function: report from the Standardisation Sub-committee of the International Continence Society. Neurourol Urodyn 2002;21:167-78.

4. Liberman JN, Hunt TL, Stewart WF, Wein A, Zhou Z, Herzog AR, et al. Health-related quality of life among adults with symptoms of overactive bladder: results from a U.S. community-based survey. Urology 2001;57:1044-50.

5. Milsom I, Abrams P, Cardozo L, Roberts RG, Thuroff J, Wein AJ. How widespread are the symptoms of an overactive bladder and how are they managed? A population-based prevalence study. BJU Int 2001;87:7606.

6. Jo JK, Lee S, Kim YT, Choi HY, Kim SA, Choi BY, et al. Analysis of the risk factors for overactive bladder on the basis of a survey in the community. Korean J Urol 2012;53:541-6.

7. Sexton CC, Coyne KS, Thompson C, Bavendam T, Chen CI, Markland A. Prevalence and effect on health-related quality of life of overactive bladder in older Americans: results from the epidemiology of lower urinary tract symptoms study. J Am Geriatr Soc 2011;59:1465-70.

8. Stewart WF, Van Rooyen JB, Cundiff GW, Abrams P, Herzog AR, Corey R, et al. Prevalence and burden of overactive bladder in the United States. World J Urol 2003;20:327-36.

9. Wein AJ, Rovner ES. Definition and epidemiology of overactive bladder. Urology 2002;60(5 Suppl 1):7-12.

10. Itoh Y, Yamada S, Konoeda F, Koizumi K, Nagata H, Oya $\mathrm{M}$, et al. Burden of overactive bladder symptom on quality of life in stroke patients. Neurourol Urodyn 2013;32:428-34.

11. Minassian VA, Drutz HP, Al-Badr A. Urinary incontinence as a worldwide problem. Int J Gynaecol Obstet 2003;82:327-38.

12. Stoffel JT, Peterson AC, Sandhu JS, Suskind AM, Wei JT, Lightner DJ, et al. AUA white paper on nonneurogenic chronic urinary retention: consensus definition, 
treatment, algorithm, and outcome endpoints. J Urol 2017;198:153-60.

13. Yamaguchi O, Nishizawa O, Takeda M, Yokoyama O, Homma Y, Kakizaki H, et al. Clinical guidelines for overactive bladder. Int J Urol 2009;16:126-42.

14. Homma Y, Yoshida M, Seki N, Yokoyama O, Kakizaki $\mathrm{H}$, Gotoh M, et al. Symptom assessment tool for overactive bladder syndrome: overactive bladder symptom score. Urology 2006;68:318-23.

15. Jeong SJ, Homma Y, Oh SJ. Korean version of the overactive bladder symptom score questionnaire: translation and linguistic validation. Int Neurourol J 2011;15: 135-42.

16. Gandek B, Sinclair SJ, Kosinski M, Ware JE Jr. Psychometric evaluation of the SF-36 health survey in Medicare managed care. Health Care Financ Rev 2004;25:525.

17. Patel M, Coshall C, Rudd AG, Wolfe CD. Natural his- tory and effects on 2-year outcomes of urinary incontinence after stroke. Stroke 2001;32:122-7.

18. Tibaek S, Gard G, Klarskov P, Iversen HK, Dehlendorff C, Jensen R. Prevalence of lower urinary tract symptoms (LUTS) in stroke patients: a cross-sectional, clinical survey. Neurourol Urodyn 2008;27:763-71.

19. Williams MP, Srikanth V, Bird M, Thrift AG. Urinary symptoms and natural history of urinary continence after first-ever stroke: a longitudinal populationbased study. Age Ageing 2012;41:371-6.

20. Willis-Gray MG, Dieter AA, Geller EJ. Evaluation and management of overactive bladder: strategies for optimizing care. Res Rep Urol 2016;8:113-22.

21. Egan KB. The epidemiology of benign prostatic hyperplasia associated with lower urinary tract symptoms: prevalence and incident rates. Urol Clin North Am 2016;43:289-97. 